\title{
TELOCENTRIC FRAGMENT CHROMOSOMES IN TRILLIUM GRANDIFLORUM
}

\author{
A. RUTISHAUSER \\ Institut für allgemeine Botanik, Universität Zürich
}

Received I 4.v.60

IN a former paper (Rutishauser, I956) two types of fragment chromosomes have been reported for Trillium grandiflorum: standard type $(s)$ with submedian centromeres and telocentrics $(t)$. By scoring $s$-chromosomes in triploid endosperms of the crosses $\mathrm{O} \times s$ and $s \times \mathrm{O}$ their distribution could be ascertained. It is normal on the male side; on the female side more than 8o per cent. of all endosperms contained fragment chromosomes, which proves that $s$-chromosomes are preferentially included in the functioning dyad-cell (preferential segregation).

In order to get more information concerning the mechanism of distribution of fragment chromosomes, plants with $t$-chromosomes have been included in a new series of cross experiments. As Roman (1947) pointed out, in maize, interchange-chromosomes carrying terminal centromeres and one-third of the proximal part of a (heterochromatic) B-chromosome show directed non-disjunction in the second mitotic division of the pollen grain, whereas interchange chromosomes carrying the other two-thirds of the B-chromosome, but provided with the subterminal centromere of chromosome 4 , segregate normally. Roman concluded that the position of the centromere might be responsible for this unorthodox chromosome distribution. It has been the aim of the new series of cross experiments mentioned above to find out if Roman's hypothesis is also valid for the (euchromatic) fragment chromosomes of Trillium grandiflorum, whose deviating distribution takes place in the first meiotic division, or if preferential segregation is due to other properties of the chromosomes.

\section{PREFERENTIAL SEGREGATION}

Crosses of the type $\mathrm{O} \times t$ and $t \times \mathrm{O}$ have been carried out as described earlier for standard fragment chromosomes (Rutishauser, I956), and $t$-chromosomes have again been scored in the endosperms. The results obtained correspond exactly to those reported for $s$-chromosomes (table $\mathrm{I}$ ). Whereas in $\mathrm{O} \times t$-crosses $t$-chromosomes show normal distribution, in $t \times \mathrm{O}$-crosses 86.8 per cent. of all endosperms revealed two $t$-chromosomes (due to fusion of two polar nuclei, endosperms with two $t$-chromosomes in $t \times \mathrm{O}$-crosses correspond to endosperms with one telocentric in $\mathrm{O} \times t$-crosses). Crosses carried out with parent plants both containing $t$-chromosomes confirm these results. In $t \times t$-crosses, endosperms provided with two or three 
$t$-chromosomes, respectively, correspond to $t t$-endosperms of the $t \times \mathrm{O}$-crosses. Their frequency is $8 \mathrm{I} \cdot 7$ per cent., almost the same as that of $t t$-endosperms in $t \times \mathrm{O}$-crosses. Similar results have been obtained in corresponding crossing experiments with plants containing $s$-chromosomes (table $\mathrm{I}$ ).

In Trillium grandiflorum, so far as segregation of fragment chromosomes is concerned, no differences exist between standard fragments

TABLE I

Segregation of $\mathrm{f}$-chromosomes in $O \times \mathrm{f}, \mathrm{f} \times O$ and $\mathrm{f} \times \mathrm{f}$-crosses

\begin{tabular}{|c|c|c|c|c|c|c|c|c|c|c|c|c|c|}
\hline \multirow{3}{*}{ Species } & & \multirow{3}{*}{\multicolumn{2}{|c|}{$\begin{array}{l}\text { Type of } \\
f \text {-chrom. }\end{array}$}} & \multirow{3}{*}{\multicolumn{2}{|c|}{ Chromaticity }} & \multirow{3}{*}{\multicolumn{3}{|c|}{ Scored in }} & \multicolumn{5}{|c|}{$\mathrm{O} \times f$} \\
\hline & & & & & & & & & \multicolumn{4}{|c|}{ No. of $f$-chrom. } & \multirow{2}{*}{$\begin{array}{c}\text { Per cent. } \\
\text { male } \\
\text { gametes } \\
\text { with } f \text {-chr. }\end{array}$} \\
\hline & & & & & & & & & o & & $\mathbf{I}$ & 2 & \\
\hline $\begin{array}{l}\text { Plantago serraria } \\
\text { Lilium callosum } \\
\text { Trillium grandiflorum } \\
\text { Trillium grandiflorum }\end{array}$ & $\begin{array}{l}\dot{.} \\
\dot{.}\end{array}$ & \multicolumn{2}{|c|}{$\begin{array}{l}s \\
t \\
s \\
t\end{array}$} & \multicolumn{2}{|c|}{$\begin{array}{l}\mathrm{H} \\
\mathrm{E} \\
\mathrm{E} \\
\mathrm{E}\end{array}$} & \multicolumn{3}{|c|}{$\begin{array}{l}\text { seedlings } \\
\text { seedlings } \\
\text { endosperms } \\
\text { endosperms }\end{array}$} & \multicolumn{2}{|c|}{$\begin{array}{r}\text { I I I } \\
45 \\
\text { I } 66 \\
29\end{array}$} & $\begin{array}{r}92 \\
54 \\
183 \\
3^{2}\end{array}$ & $\begin{array}{l}2 \\
\cdots \\
\cdots \\
\cdots\end{array}$ & $\begin{array}{l}45 \cdot 9 \\
54 \cdot 5 \\
52 \cdot 4 \\
52 \cdot 6\end{array}$ \\
\hline \multirow{3}{*}{ Species } & \multicolumn{6}{|c|}{$f \times \mathrm{O}$} & \multicolumn{6}{|c|}{$f \times f$} & \multirow{3}{*}{ Author } \\
\hline & \multicolumn{4}{|c|}{ No. of $f$-chrom. } & \multirow{2}{*}{\multicolumn{2}{|c|}{$\begin{array}{l}\text { Per cent. } \\
\text { female } \\
\text { gametes } \\
\text { with } f \text {-chr. }\end{array}$}} & \multicolumn{4}{|c|}{ No. of $f$-chrom. } & \multirow{2}{*}{\multicolumn{2}{|c|}{$\begin{array}{l}\text { Per cent. } \\
\text { female } \\
\text { gametes } \\
\text { with } f \text {-chr. }\end{array}$}} & \\
\hline & 0 & I & 2 & 3 & & & o & I & 2 & 3 & & & \\
\hline Plantago serraria & 76 & 183 & $\ldots$ & $\ldots$ & $73 \cdot 5$ & & 34 & 93 & 6 I & $\ldots$ & & $\ldots$ & Fröst, I959 \\
\hline Lilium callosum & I 6 & 83 & I & $\cdots$ & $8_{4} \cdot \mathrm{C}$ & & 8 & 53 & $3^{8}$ & I & & $\cdots$ & $\begin{array}{l}\text { Kayano, } \\
\text { I056 }\end{array}$ \\
\hline Trillium grandiflorum & 27 & 2 & I 75 & I & $86 \cdot 8$ & & 5 & 3 & 33 & $2 \mathrm{I}$ & & $7 \cdot 1$ & Rutishauser, \\
\hline Trillium grandiflorum & IO & 3 & 63 & $\cdots$ & $86 \cdot 8$ & & $\cdots$ & 2 & 7 & 2 & & $1 \cdot 7$ & \\
\hline
\end{tabular}

$\mathrm{t}=$ telocentric. $\quad \mathrm{s}=$ standard-f-chromosome. $\quad \mathrm{H}=$ heterochromatic. $\quad \mathrm{E}=$ euchromatic.

and telocentrics. Obviously, the position of the centromere has no influence on the distribution of B-chromosomes in the course of the first meiotic division. The same conclusion may be drawn from the results of crossing experiments with Plantago serraria (Fröst, I959) whose B-chromosomes are of the standard type and from crosses with specimens of Lilium callosum (Kayano, I956) containing telocentric B-chromosomes (table I).

Therefore, Roman's hypothesis is not applicable to B-chromosomes revealing preferential segregation. Nor are heterochromatic blocks likely to be responsible for this mechanism of numerical increase as Roman (1950) and Longley (I956) suggested in the case of maize. Both standard and telocentric fragments of Trillium grandiflorum are 


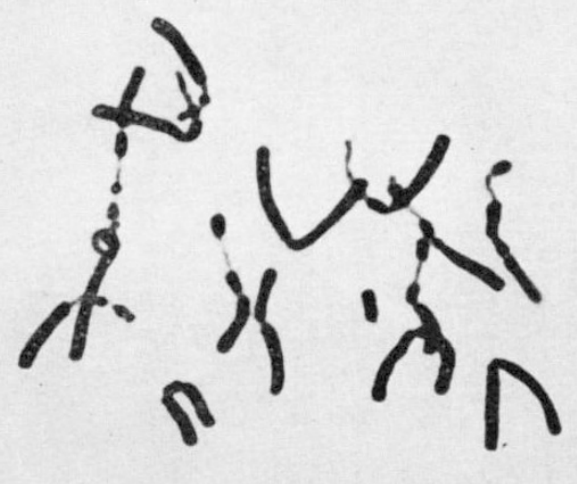

1

3

5
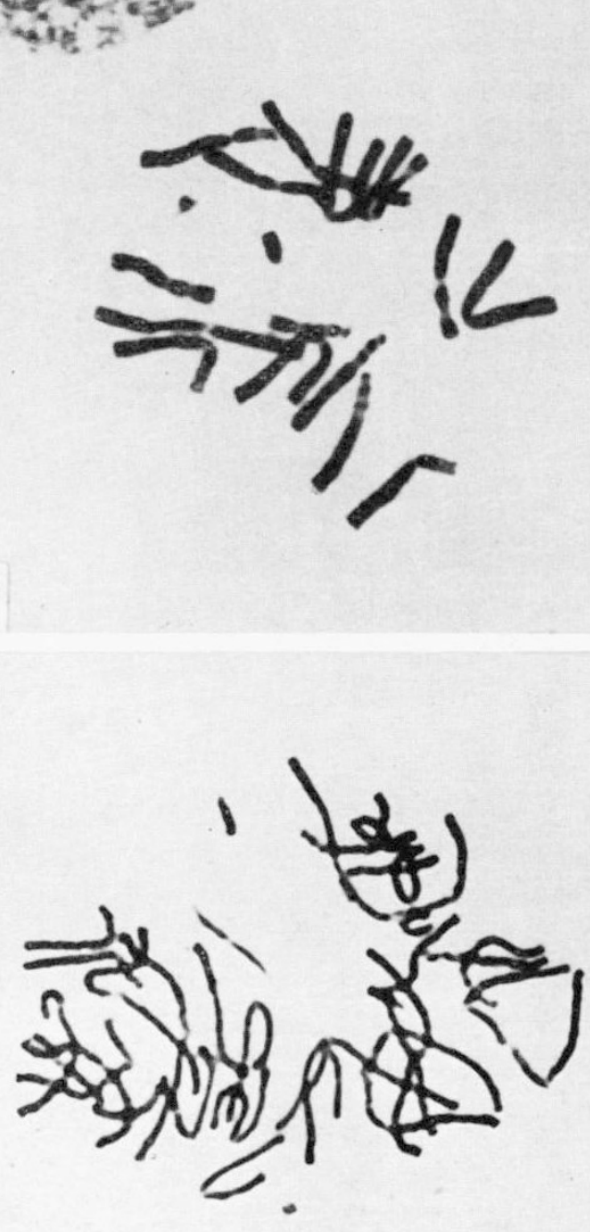

3

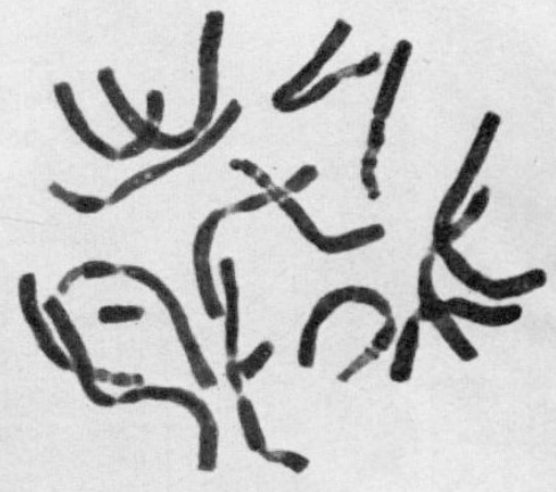

2
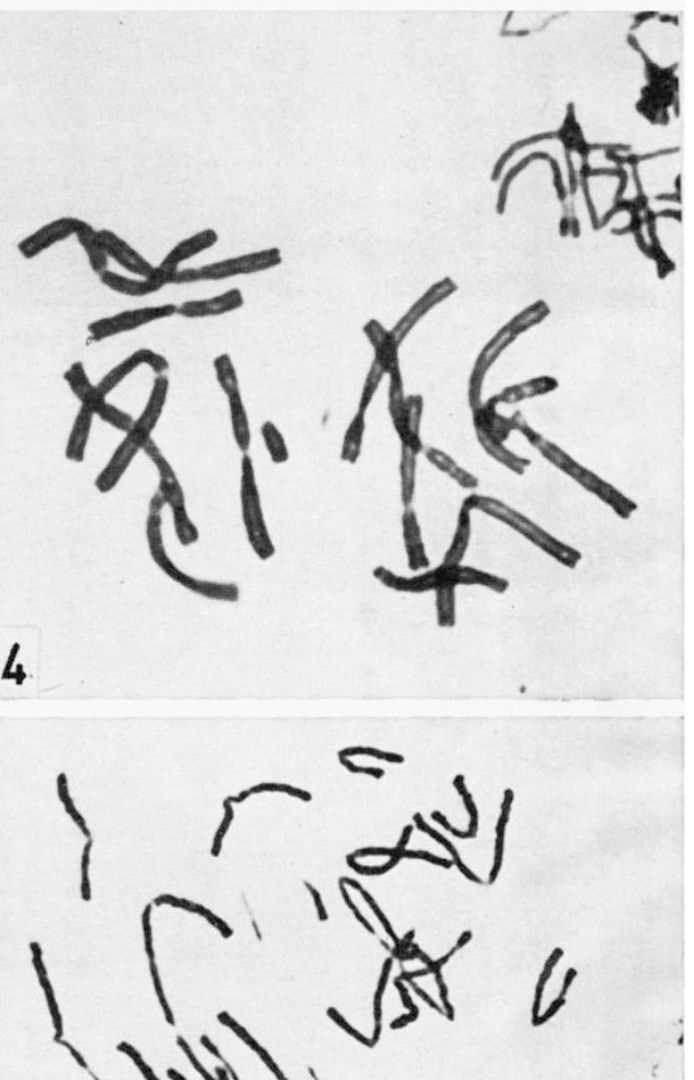

6

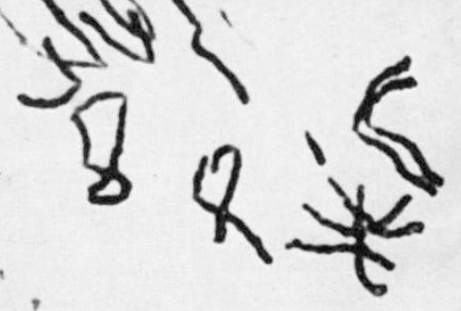



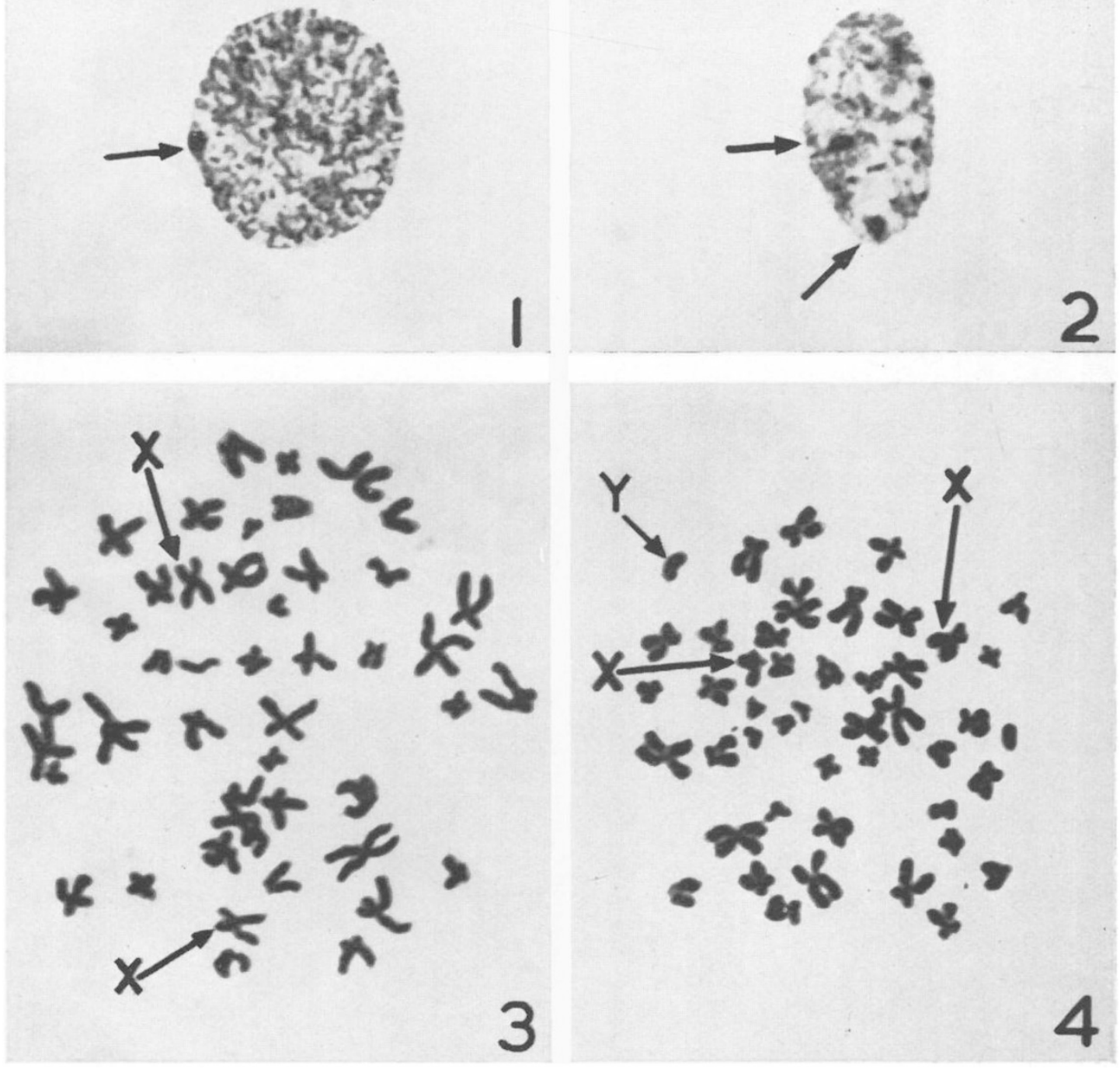

Figs. I-2.-Nuclei of buccal epithelial cells with one (fig. I) and two (fig. 2) sex chromatin particles. c. $\times \mathbf{I} 500$.

FIGs. 3-4.-C-mitotic metaphases of bone-marrow cells differing in sex chromosome constitution; fig. 3 is $\mathrm{XX}$ and fig. $4 \mathrm{XXY}$. c. $\times 2200$. 
entirely euchromatic. For this reason it seems probable that fragment chromosomes of Trillium are deviating from ordinary chromosomes in the properties of their centromeres.

\section{STABILITY OF TELOCENTRIC FRAGMENT CHROMOSOMES}

Structural changes of centromeres may be expressed in one of the following ways (Marks, 1957): failure of congression, nondisjunction, misdivision, production of isochromosomes. In Trillium grandiflorum no investigations on meiotic divisions have been carried out. Our statements on stability of fragment chromosomes have been inferred from observations in the endosperms. They show that standard fragments are highly stable; only three out of 205 endosperms of the cross $s \times \mathrm{O}$ revealed numbers of fragment chromosomes differing from those expected ( $\mathrm{I}$ or 3 ) and in $\mathrm{O} \times s$-crosses no deviation at all occurred.

The same is true for $t$-chromosomes. No signs of non-disjunction and production of isochromosomes could be detected. Apart from failure of congression, which is presumably one of the causes for preferential segregation, telocentric fragments seem to be quite normal and stable (plate, figs. I and 2). However, telocentrics are more often subjected to structural changes of chromosome arms than $s$-fragments. Whereas in $4 \mathrm{I} 8$ endosperms carrying $s$-fragments not the slightest structural change of the fragments occurred, remarkable alterations of chromosome-form and -size have been found in two endosperms out of Iog carrying $t$-chromosomes. In one instance a break could be observed in one of the two teleocentrics present, followed by reunion of the acentric fragment with the centromere. So a new standard chromosome was built up, which, however, was not identical with the ordinary $s$-fragment.

In a second endosperm, 63 metaphases and anaphases which could be analysed contained one normal fragment chromosome and one telocentric of varying size. Its variability extended from chromosomes measuring half the length of normal telocentrics (plate, fig. 4) to those consisting of bare centromeres (plate, fig. 3). Bridges detected in anaphases indicate that some kind of a breakage-fusion-bridge cycle leads to this change of telocentrics (plate, figs. 5,6 ).

The two instances of disintegration of telocentrics prove that $t$-chromosomes are less stable than $s$-chromosomes. This finding is

\section{Plate}

Microphotographs of chilled endosperm metaphases and anaphases.

FIG. I.-Metaphase with one telocentric. $\times 900$.

FiG. 2.-Metaphase with two telocentrics. $x_{1}$ Ioo.

Figs. 3-4.-Metaphases with one normal and one diminishing telocentric. $\times 900 / 1100$. FIGs. 5-6.-Anaphases. Separation of normal and diminishing telocentrics. $\times 900$. 
consistent with Darlington's and Shaw's observation that three types of $t$-chromosomes occur in Trillium, whereas in most of the species investigated only one type of $s$-chromosome has been found (Darlington and Shaw, I959). Since both cases of fragment disintegrations occurred in daughter plants of $t \times \mathrm{O}$-crosses, and since only one telocentric has been affected, the initiation of structural changes has presumably taken place in the course of embryosac- or endospermdevelopment.

\section{DISCUSSION}

According to Roman (I947), a special type of division is required for maintaining numerical increase of B-chromosomes. In grasses it is the first or the second mitotic division of the pollen grain, in Trillium, Lilium and Plantago the first meiotic division.

Up to now, preferential segregation has only been reported for EMCs. As Kayano (I957) pointed out, it is due to failure of congression of univalent B-chromosomes in Metaphase I. In most EMCs B-chromosomes are not included in the equatorial region but are lying preferentially on the micropylar side. Kayano concluded that " preferential segregation has an intimate bearing on the developmental polarity or gradient in EMC" (Kayano, I957, p. 737). Presumably, this mechanism is similar to that found in pollen grain mitosis and consists in an asymmetry of the spindle of the first meiotic division. Such asymmetric spindles, or at least an asymmetric position of the spindles in EMCs, have indeed been found in a variety of species (Schnarf, I929). They seem to be common in plants with an embryosac-development of the Allium-type, and in the case of Trillium grandiflorum the existence of asymmetric spindles may be inferred from the fact that the non-functioning micropylar dyad-cell is smaller than the chalazal dyad-cell (Ernst, I902).

In PMCs preferential segregation does not take place, nor could it possibly be detected, even if asymmetric spindles in the first meiotic divisions occurred in them, for, as a rule, all four microspores are functional. Therefore, preferential segregation is always intimately connected with megaspore formation and depends on properties characteristic of the production of female gametes. It is likely that no special mechanism had to be built up for creating and maintaining preferential segregation of B-chromosomes, as is presumably also the case with the mechanism found in grasses which leads to directed non-disjunction of B-chromosomes. In both cases B-chromosomes make use of mechanisms already existing, mechanisms which are also present in plants devoid of B-chromosomes.

If this is true, deviating segregation of fragment chromosomes depends entirely on special properties of B-chromosomes which are usually not present in ordinary chromosomes. In rye, directed nondisjunction is correlated with the presence of a conspicuous knob near the end of the long arm of the standard accessory (Müntzing, I958, p. 460). 
In Trillium grandiflorum such a knob is not likely to occur. Fragments of various types and size show exactly the same type of segregation. Since fragment chromosomes of Trillium grandiflorum are entirely euchromatic, heterochromatin may also be excluded as a possible cause for preferential segregation. Nor is this type of chromosome distribution due to the position of the centromere. Therefore, one might suggest that in this species it is the structure of the centromere which has been subjected to alterations that prevent normal congression of B-chromosomes in the course of the first meiotic division.

But even this seems not to be likely, considering the fact that neither submedian nor terminal centromeres show any sign of weakness. We are, therefore, inclined to impute the unorthodox distribution of B-chromosomes merely to their univalent condition. The following facts are in favour of this hypothesis:

(I) Preferential segregation was shown for ordinary univalent A-chromosomes of Rosa canina (Täckholm, r922).

(2) Univalent X-chromosomes of Talaporia tubulosa revealed preferential segregation in temperature experiments (Seiler, r920).

(3) In $2 \mathrm{~B} \times \mathrm{O}$-crosses $\mathrm{B}$-chromosomes of Plantago serraria, whose bivalent formation is suppressed, segregate preferentially (Fröst, 1959). On the other hand, 2B-plants of Lilium callosum combine bivalent-formation with normal distribution of B-chromosomes, although a certain amount of preferential segregation occurs (Kayano, I 956$)$.

Obviously, preferential segregation is at least partially bound to univalent condition of B-chromosomes. Lack of pairing of B-chromosomes may, therefore, be one of the causes for this deviating type of chromosome distribution.

\section{SUMMARY}

I. Preferential segregation has been demonstrated for telocentric and standard fragment chromosomes in Trillium grandiflorum. The position of the centromere does not influence the segregation of fragment chromosomes.

2. It may be concluded that preferential segregation depends:

(a) on properties characteristic for megaspore formation, and

(b) on univalent condition of fragment chromosomes.

3. Telocentrics are less stable than standard fragments. Structural changes and disintegration of telocentrics occur as a consequence of chromosome breakage and reunion.

Acknowledgments. - This work has been carried out with the support of the Swiss National Foundation. Special thanks go to my assistant, Miss J. Botta, for conscientious cooperation. 


\section{REFERENCES}

DARlington, C. D., AND SHAw, G. W. I959. Parallel polymorphism in the heterochromatin of Trillium species. Heredity, I3, 89- I 2 I.

ERnst, A. I 902. Chromosomenreduction, Entwickelung des Embryosacks und Befruchtung bei Paris quadrifolia I. und Trillium grandiflorum. Salisb. Flora Erg.bd. I 902, 5-50.

FRösT, s. I959. The cytological behaviour and mode of transmission of accessory chromosomes in Plantago serraria. Hereditas, 45, I $9 \mathrm{I}-2 \mathrm{I}$ o.

Kayano, H. I956. Cytogenetic studies in Lilium callosum. II. Preferential segregation of a supernumerary chromosome. Mem. Fac. Sci. Kyushu Univ. (E) Biol., $I$, I 59 -I 85 .

KAyano, H. I957. III. Preferential segregation of a supernumerary chromosome in EMCs. Proc. 7ap. Acad., 33, 553-558.

LONGLEY, A. E. I956. The origin of diminutive B-type chromosomes in maize. Am. 7. Bot., 43, 18-22.

Marks, G. E. I957. Telocentric chromosomes. The Am. Nat., 9I, 223-232.

MÜNTZING, A. I95I. The meiotic pairing of iso-chromosomes in rye. Port. Acta Biol. Ser. A, R. B. Goldschmidt, 83 I-86o.

müntzing, A. I958. A new category of chromosomes. Proc. $X$ Int. Congr. Genet., I, $453-467$.

ROMAN, H. I947. Mitotic nondisjunction in the case of interchanges involving the B-type chromosome in maize. Genetics, 32, 39 I-409.

ROMAN, H. I950. Factors affecting mitotic nondisjunction in maize. Crenetics, $35,132$.

RUTISHaUser, A. 1956. Genetic of fragment chromosomes in Trillium grandiflorum. Heredity, IO, I 95-204.

SEILER, J. I92I. Fxperimentelle Beeinflussung der geschlechtsbestimmenden Reifeteilung bei Talaporia tubulosa Retz. Arch. Zellforschung, 15, 249-268.

тӓскноцм, G. 1922. Zytologische Studien über die Gattung Rosa. Acta Hort. Berg., 7, 97-381.

\section{Additional reference}

SCHnARF, K. I927. Embryologie der Angiospermen. Handb. der Pflanzenanat., II, Abt. 2, T. 